\title{
Intervention study on Saccharomyces boulardii with proton pump inhibitor (PPI)-based triple therapy for Helicobacter pylori related peptic ulcer
}

\author{
Yi Chu, Hongyi Zhu, Yuqian Zhou, Liang Lv and Jirong Huo* \\ Department of Gastroenterology, The Second Xiangya Hospital of Central South University, Changsha 410011, China.
}

Accepted 29 October, 2012

\begin{abstract}
The study was undertaken to investigate the efficacy and safety of Saccharomyces boulardii combined with proton pump inhibitor (PPI)-based triple therapy for Helicobacter pylori related peptic ulcer. One hundred patients with $H$. pylori infection were randomized in two groups: intervention and control group. Both groups were treated with the standard triple eradication therapy (omeprazole, amoxicillin and clarithromycin). The effective rate of the improvement in the treatment group was $96.0 \%$, and was significantly higher than the control group $(62.0 \%)\left(x^{2}=6.899, \mathrm{P}<0.01\right)$. The $\mathrm{pH}$ of the two groups was also elevated after the treatment $(P<0.05, P<0.05)$; the positive culture rate of bacteria increased obviously and there was significant difference between the two groups $(P<0.05)$. The eradication rate of $\boldsymbol{H}$. pylori in the treatment group was $84.4 \%$ and was significantly higher than the control group $(64.4 \%)\left(x^{2}=5.848, P<0.01\right)$. In addition, the rate of recurrence in the treatment group was $10.0 \%$, while in the control group it was $26.0 \%$ after treated for one year $\left(x^{2}=11.584, P<0.01\right)$. There was significant difference in the rate of adverse events between the two groups (15.6 and $57.8 \%$ of the treatment group and control group, respectively; $x^{2}=18.936, P<0.01$ ). Therefore, $S$. boulardii with PPI-based triple therapy for peptic ulcer is effective with a low recurrence rate and can reduce the incidence of adverse events.
\end{abstract}

Key words: Peptic ulcer, Helicobacter pylori, Saccharomyces boulardii, proton pump inhibitor (PPI)-based triple therapy.

\section{INTRODUCTION}

Peptic ulcer (PU) is a common infectious disease in the digest system, including gastric ulcer (GU) and duodenal ulcer (DU). Approximately $10 \%$ of the population has experienced $\mathrm{PU}$ in certain period during the life time (Gissbert and Pajares, 2010). However, the morbidity of this disease has increased along with the change in people life style in recent years, such as overwork, mood fluctuations, smoke, heavy drink and eating disorders. The mechanisms of PU are complicated and are

*Corresponding author. E-mail: ehcobaxia@126.com. Fax: 860731-85533525. considered closely related to the hyperchlorhydria and Helicobacter pylori infection. H. pylori, a Gram-negative bacterium that colonizes the gastric mucosa by producing a potent urease and inducing chronic inflammation, is a significant etiologic agent for gastric ulcers and carcinomas (WHO, 2012: http://www.who.int/vaccine_research/documents/Helicoba cter_pylori/en/).

The diagnosis and treatment of upper gastrointestinal disease has revolutionized since $H$. pylori was indentified and cultured (Kengo et al., 2005). H. pylori infection is associated with a wide spectrum of gastrointestinal diseases that vary from asymptomatic gastritis to peptic ulceration, gastric carcinoma and mucosa-associated 
lymphoid tissue lymphoma. It is reported that $H$. pylori can injure gastric mucosa directly and secrete many kinds of enzymes and metabolites to initiate peptic ulcer (Kuo, 2005). Meanwhile, $H$. pylori can also injure gastric mucosa indirectly and generate $H$. pylori antibody, which leads to peptic ulcer by injury on the host immunity. Reports of the effectiveness of $H$. pylori eradication therapy are mounting (Chung et al., 2012; Kuo et al., 2012), suggesting the vital value to eradicate $H$. pylori in curing ulcer, preventing recurrence and reducing complications.

Generally, $H$. pylori infection is easy to be ignored because it does not have any clinically significant complication at the very beginning in a majority of patients. Currently, 1 to 2 weeks of PPI-based triple therapy is regarded as the regular treatment for $\mathrm{H}$. pylori-infectious peptic ulcer. It can cure ulcer efficiently though inhibiting gastric acid secretion and $H$. pylori elimination quickly. However, it was found that the resistance of $H$. pylori to clarithromycin and amoxicillin were high in a study of drug resistance in bacteria (Ahmed and Sechi, 2005). Furthermore, the incidences of adverse events increase, which severely affect patient compliance and limit the overall therapeutic value of the treatment. Recently, interest in the improvement of eradication rate of $\mathrm{H}$. pylori appears to be mounting, especially the protocol of PPIbased triple therapy combined with microbial agents (Xia et al., 2007; Xu et al., 2010). Pilot researches by Tsimmerman et al., (2010), Lakovenko et al., (2006) and Goldman et al., (2006) suggest micro-ecological preparations may elevate the eradication rate of $H$. pylori. Therefore, in recent years, to investigate the potential role of Saccharomyces boulardii in reducing $\mathrm{H}$. pylori treatment-related side effects while improving the eradication rate, we added $S$. boulardii to PPI-based triple therapy to cure $H$. pylori-infectious $\mathrm{PU}$ and the results show a satisfactory clinical effect for the prevention and treatment of the disease.

\section{MATERIALS AND METHODS}

A total of one hundred patients with $H$. pylori related peptic ulcer, who were taking therapy in our hospital between September 2009 and January 2011 were randomly included in the study. According to the diagnostic criteria of Report of Chinese Medical Association's Second National Academic Seminar on H. pylori (Zhou et al., 1997) and $H$. pylori Consensus Opinions (Zhang, 2004), these patients were all diagnosed as peptic ulcer by gastroscope and $H$. pylori infection were detected as positive through hemotoxylin and eosin (HE) staining and rapid urease testing of the gastric biopsy specimens obtained by endocytoscopy and each of patients never received treatment with $\mathrm{PPI}$ or antibiotics 2 weeks prior to their participation in the study. The onset age of the patients (68 males and 32 females) ranged from 17 to 76 years, with an average of (38.27 \pm 11.81$)$ years, and they suffered from the disease for (8.83 \pm 4.29 ) years (range from 5 month to 27 years). Of the 100 patients, 63 suffered from duodenal ulcer, 25 were with complex ulcer and 12 were of gastrohelcosis. Moreover, in this study, sex and age were not significantly different in treatment group and control group( $\mathrm{P}>$ 0.05). Included subjects were instructed to read carefully the protocol information and to sign a written consent form according the good clinical practice. The study was approved by the local ethical committee.

The 100 subjects included in the study were randomly averaged into two groups: the control and treatment group. The group administered with the standard triple PPI therapy was set as control group: omeprozole $20 \mathrm{mg}$ (Xuchang Orson Pharmaceutical Company Limited, batch record: 060821) associated with amoxicillin $1.0 \mathrm{~g}$ (Shandong Luhang Pharmaceutical Company Limited, batch record: H19993034) and clarothromycin $0.5 \mathrm{~g}$ (Abbott Laboratories' Shanghai Pharmaceutical Company Limited, batch record: 916205) for 14 days (twice per day). And in addition to administration of the standard triple PPI therapy, $S$. boulardii (Laboratories Biocodex, $250 \mathrm{mg} / \mathrm{bag}$, twice/day, b.i.d., for 14 days) was administered to the rest as the treatment group. During the treatment, patients were asked to avoid spicy incentives, greasy food, heavy drinking and overwork. A second gastroscopy will be performed after the treatment for one year to evaluate the efficacy and safety of the therapy.

\section{Treatment effect measures}

The ulcer recovery, gastric phase and gastric mucosal tissue pathology changes were evaluated by gastroscope before and after treatment to evaluate the clinical effect. Recovery: ulcer and inflammation around it disappear; powerfully effective: ulcer disappears but with inflammation; effective: the ulcer size was lessened over 50\%; invalid: the ulcer size was lessened to less than $50 \%$ (Lin and Liu, 2004). Recovery, powerfully effective and effective were the basis for evaluating the efficiency of the treatment.

\section{Main outcome measures}

The main outcomes include:

1. The $\mathrm{pH}$ of the succus gastricus: using $\mathrm{pH}$ test paper to determine the $\mathrm{pH}$ value before and after 14 days treatment;

2. Culture and identifying the bacteria in the succus gastricus: $1 \mathrm{ml}$ succus gastricus was added to $5 \mathrm{ml}$ broth tube, then cultured for 24 to $48 \mathrm{~h}$ in a common bacteria culture box $\left(37^{\circ} \mathrm{C}\right)$. Bacteria were separated and identified by using automatic detection machine;

3. Follow-up one year to evaluate the eradication rate of $H$. pylori by the symptoms, signs and reviewing the rapid urease test. If the test was negative, effective; if the test was positive, invalid; and then the eradication rate was counted and;

4. Evaluate the incidence of peptic ulcer recurrence and survey the adverse events during the treatment.

\section{Statistical analysis}

A comparison of continuous data between the two study groups was carried out using the Student's t-test after evaluating the equality of variances. Discontinuous variables were compared by the Chi-square test. All values are expressed as mean \pm standard error (SE) of mean. Probability values less than 0.05 were considered statistically significant (analysis was performed using SPSS for Windows, Version 13.0).

\section{RESULTS}

\section{Efficacy}

The total effective rate of the improvement in the 
Table 1. The comparison to clinical effect of the two groups.

\begin{tabular}{lcccccc}
\hline Group & $\mathbf{n}$ & Recovery & Powerfully effective & Effective & Invalid & Efficiency (\%) \\
\hline Treatment & 50 & $31(62.0)$ & $14(28.0)$ & $3(6.0)$ & $2(4.0)$ & $96.0^{*}$ \\
Control & 50 & $14(28.0)$ & $10(20.0)$ & $7(14.0)$ & $19(38.0)$ & 62.0 \\
\hline
\end{tabular}

${ }^{*} P<0.05$, compared to the control group.

Table 2. The $\mathrm{pH}$ and bacteria of the two groups.

\begin{tabular}{lccccc}
\hline \multirow{2}{*}{ Group } & \multirow{n}{n}{} & \multicolumn{2}{c}{$\mathbf{p H}$} & \multicolumn{2}{c}{ Positive rate of the bacteria (\%) } \\
\cline { 3 - 6 } & & Before & After & Before & After \\
\hline Treatment & 50 & $1.46 \pm 0.49$ & $4.15 \pm 1.38^{\mathrm{ab}}$ & 0 & $64.0(32 / 50)^{\mathrm{C}}$ \\
Control & 50 & $1.47 \pm 0.51$ & $3.07 \pm 1.02^{\mathrm{a}}$ & 0 & $42.0(21 / 50)$ \\
\hline
\end{tabular}

The comparison of the $\mathrm{pH}$ between the two groups before the treatment with the $\mathrm{pH}$ after the treatment: $t=9.157,6.728,{ }^{a} P<0.01$; after the treatment, the comparison of the $\mathrm{pH}$ between the two groups: $t=4.355,{ }^{b} P<0.01$; the positive rate of the bacteria culture in the treatment groups was $x^{2}=4.355,{ }^{c} P<0.01$, compared to the control group.

Table 3. The eradication rate of the two groups.

\begin{tabular}{lcccc}
\hline Groups & n & Effective & Invalid & Rate (\%) \\
\hline Treatment & 50 & $42(84.0)$ & $7(14.0)$ & $84.0^{*}$ \\
Control & 50 & $32(64.0)$ & $18(36.0)$ & 64.0 \\
\hline
\end{tabular}

${ }^{*} P<0.05$, compared to the control group.

treatment group was $96.0 \%$, and was significantly higher than the control group $(62.0 \%)$ and there was significant difference between the two groups $\left(x^{2}=6.899, \mathrm{P}<0.01\right)$ (Table 1).

\section{The $\mathrm{pH}$ and bacteria culture}

There was no significant difference in the $\mathrm{pH}$ of the succus gastricus between the two groups before the treatment $(\mathrm{P}>0.05)$. However, the $\mathrm{pH}$ of the two groups increased after the treatment $(P<0.05)$ and there was significant difference between the treatment group and the control group $(P<0.05)$. Moreover, the bacteria tests of the two groups were negative before the treatment, but after the treatment, the positive rate of the bacteria increased markedly $(P<0.01)$ and the difference was significant between the two groups $(P<0.05)$ (Table 2$)$.

\section{Eradication rate of $\boldsymbol{H}$. pylori}

The eradication rate of $H$. pylori was 84.4 and $64.4 \%$ in the treatment and control group, respectively presenting a striking difference $\left(x^{2}=5.848, P<0.01\right)$ (Table 3$)$.

\section{Recurrence rate of peptic ulcer}

After one year therapy, the recurrence rate of peptic ulcer was $10.0 \%$ (5 in 50 patients) in the treatment group, while the rate was $26.0 \%$ (13 in 50 ) in the control group, suggesting that the rate of the treatment group was lower than that of the control group. There was significant difference between the two groups $\left(x^{2}=11.584\right)(P<0.01)$.

\section{Adverse events}

There was no serious side effect in the two groups and no symptomatic treatment. The most common side effects were mild to moderate and self-limiting, such as nausea, vomiting, diarrhea, melena and dizziness, etc. The occurrence of side effects in the treatment group was notably lower than that in the control group (15.6 and $57.8 \%$, respectively), and difference was significant $\left(x^{2}=\right.$ 18.936, $\mathrm{P}<0.01$ ) (Table 4).

\section{DISCUSSION}

HP $S$. boulardii, a strain of yeast, is a good probiotic candidate based on its safety in combination with antibiotics and its resistance to local stress. It has been suggested that $S$. boulardii, a kind of nonpathogenic yeast, may be effective and safe in preventing antibioticassociated diarrhea (AAD) (Katz, 2006) while eradicating H. pylori infection (Cremonini et al., 2002; Duman et al., 2005). S. boulardii has been noted for two main functions: (i) "immunobiotic" properties that exert antiinflammatory activity through the inhibition of the nuclear factor-kappa B (NF-jB) and modification of T-lymphocyte 
Table 4. The adverse events of the two groups.

\begin{tabular}{lccccccc}
\hline Group & $\mathbf{n}$ & Nausea & Vomiting & Diarrhea & Melena & Dizzy & Rate (\%) \\
\hline Treatment & 50 & 2 & 1 & 3 & 1 & 1 & $16.0(8 / 50)$ \\
Control & 50 & 5 & 7 & 8 & 9 & 5 & $68.0(34 / 50)$ \\
\hline
\end{tabular}

${ }^{*} P<0.05$, compared to the control group.

cell rolling and, (ii) neutralization of bacterial toxins (Czerucka and Rampal, 2002). A study indicated that $S$. boulardii powder can be engrafted in the gastrointestinal tract and tolerated to bile acid, salt and pepsin hydrolytic enzymes, and retained the concentration in a steady state in the gastrointestinal tract even administered 3 days continuously, which further help in forming the mucous membrane barrier to protect the host. In addition, it can also stick to bacteria, viruses and suppresses the pathogenic bacteria directly (Fang and Liu, 2010).

The $\mathrm{pH}$ in the gastric juice increase after anti- H. pylori and acid inhibited treatment in patients with $H$. pyloriinfectious chronic peptic ulcer, leading to damage on the stomach microecology environment for the outbreak of bacterial growth. In the present study, the positive rate of bacteria in the treatment group was significantly lower than that in the control group, revealing $S$. boulardii can inhibit bacterial overgrowth and regulate flora disturbance to maintain the balance of micro-ecological system in the stomach. Bacterial resistance and patient compliance are the two major factors that contributed to the eradication rate of HP (Lionetti et al., 2006) and the rate decreases with tolerance increase by the heavy use of antibiotics. In recent years, substantial evidence shows that probiotics may have beneficial effects in eradicating HP (Yang, 2006), reducing side-effects of antibiotics, and improving patient compliance.

In this study, the eradication rate of $H$. pylori increased by $31 \%$ after adding $S$. boulardii to the standard treatment and was consistent with the results reported above. Moreover, the side effects were significantly decreased with $S$. boulardii. The overall tolerability was significantly better in the treatment group. The findings of this study suggest that $S$. boulardii combined with other drugs can gain a synergistic effect, which enhance the efficacy and reduce side effects. Our findings suggest that the supplementation of $S$. boulardii to the standard PPI-based triple therapy is effective in treating peptic ulcer, with a low rate of recurrence and low incidence of side effects. Therefore, it may be a safe and valuable therapy for peptic ulcer.

In the present study, we conducted an intervention study on S. boulardii with PPI-based triple therapy for $H$. pylori related peptic ulcer. After the treatment, the $\mathrm{pH}$ of stomach juice was tested and the bacteria were cultured and identified, the eradication rates of $H$. pylori as well as the recurrence of peptic ulcer were assessed. Moreover, adverse events and compliance were evaluated during the treatment. Overall, the effective rates were both satisfied in the two groups but it is more effective in the treatment group (96\% in the treatment group versus $62 \%$ in the control group). When compared with the control group, the eradication rate of $H$. pylori increased dramatically by $31 \%$ in the treatment group. Moreover, the side effects were significantly decreased from 68 to $16 \%$ under the combination of $S$. boulardii. The results were consistent with the recent repots on the efficacy and safety of additional $S$. boulardii and probiotics in eradicating H. pylori (Cindoruk et al., 2007; Song et al., 2010).

The findings of this study suggest that $S$. boulardii combined with other drugs can gain a synergistic effect which enhance the efficacy and reduce side effects. Our results suggest that the supplementation of $S$. boulardii to the standard PPI-based triple therapy is effective in treating peptic ulcer with a low rate of recurrence and low incidence of side effects. Therefore, it may be a safe and valuable therapy for peptic ulcer.

\section{REFERENCES}

Ahmed N, Sechi LA (2005). Helicobacter pylori and gastroduodenal pathology: New threats of the old friend. Ann. Clin. Microbiol. Antimicrob. 4:1-5.

Chung JW, Jung YK, Kim YJ, Kwon KA, Kim JH, Lee JJ, Hahm KB, Lee SM, Jeong JY and Yun SC (2012). Ten-day sequential versus triple therapy for $H$. pylori eradication: A prospective, open-label, randomized trial. J. Gastroenterol. Hepatol. 27(11):1675-1680.

Cindoruk M, Erkan G, Karakan T, Dursun A, Unal S (2007). Efficacy and safety of Saccharomyces boulardii in the 14-day triple antiHelicobacter pylori therapy: a prospective randomized placebocontrolled double-blind study. Helicobacter 12:309-316.

Cremonini F, Di Caro S, Covino M, Armuzzi A, Gabrielli M, Santarelli L, Nista EC, Cammarota G, Gasbarrini G, Gasbarrini A (2002). Effect of different probiotic preparations on anti-Helicobacter pylori therapyrelated side effects: A parallel group, triple blind, placebo-controlled study. Am. J. Gastroenterol. 97:2744-2749.

Czerucka D, Rampal P (2002). Experimental effects of Saccharomyces boulardii on diarrheal pathogens. Microbes Infect. 4:733-739.

Duman DG, Bor S, Ozütemiz O, Sahin T, Oğuz D, Iştan F, Vural T, Sandkci M, Işksal F, Simşek I, Soytürk M, Arslan S, Sivri B, Soykan I, Temizkan A, Beşşk F, Kaymakoğlu S, Kalayc C (2005). Efficacy and safety of Saccharomyces boulardii in prevention of antibioticassociated diarrhoea due to Helicobacter pylori eradication. Eur. J. Gastroenterol. Hepatol. 17:1357-1361.

Fang Y, Liu HF (2010). The effect of Saccharomyces boulardii powder treatment for infant with autumn diarrhea. Zhejiang J. Integr. Tradit. Chin. Western Med. 20: 375-376.

Gissbert JP, Pajares JM (2010). Esomeprazole based therapy in Helicobacter pylori eradication: Meta-analysis. Dig. Liver Dis. 36:253256. 
Goldman CG, Barrado DA, Balcarce N, Rua EC, Oshiro M, Calcagno $M L$, Janjetic M, Fuda J, Weill R, Salgueiro MJ, Valencia ME, Zubillaga MB, Boccio JR (2006). Effect of a probiotic food as an adjuvant to triple therapy for eradication of Helicobacter pylori infection in children. Nutrition 22:984-988.

Katz JA (2006). Probiotics for the prevention of antibiotic-associated diarrhea and Clostridium difficile diarrhea. J. Clin. Gastroenterol. 40:249-255.

Kengo T, Kazuhiro W, Akifumi T (2005). Evaluation of 13C-urea breath test to confirm eradication of Helicobacter pylori. Jpn. J. Gastroenterol. 102:176-182.

Kuo JX (2005). The pathogenesis of peptic ulcer agent. Modern J. Integr. Chin. Tradit. Western Med. 14:152-153.

Kuo SH, Yeh KH, Wu MS, Lin CW, Hsu PN, Wang HP, Chen LT, Cheng AL (2012). Helicobacter pylori eradication therapy is effective in the treatment of early-stage $\mathrm{H}$. pylori-positive gastric diffuse large B-cell lymphomas. Blood 119:4838-4844.

Lakovenko EP, Grigor'ev Pla, Lakovenko AV, Agafonova NA, Prianishnikova AS, Sheregova EN, Vasil'ev IV, Komleva luV, Oprishchenko IV, Anashkin VA (2006). Effects of probiotic bifiform on efficacy of Helicobacter pylori infection treatment. Ter. Arkh. 78:21-26. Lin XQ, Liu J (2004). Effective observation on 60 cases of peptic ulcer treated by modified huagan decoction. Hunan J. Tradit. Chin. Med. 20:7-9.

Lionetti E, Miniello VL, Castellaneta SP (2006). Lactobacillus reuteri therapy to reduce side-effects during anti-Helicobacter pylori treatment in children: A randomized placebo controlled trial. Aliment Pharmacol. Ther. 24:1461-1468.
Song MJ, Park DI, Park JH, Kim HJ, Cho YK, Sohn Cl, Jeon WK, Kim BI (2010). The effect of probiotics and mucoprotective agents on PPIbased triple therapy for eradication of Helicobacter pylori. Helicobacter 15:206-213.

Tsimmerman IAS, Subbotina LV, Neschisliaev VA (2010). Microbial antagonism and rationale for the use of probiotics in combined therapy of Helicobacter pylori-related diseases. Clin. Med. (Mosk) 8835-8842.

WHO, World Health Organization (2012). Initiative for Vaccine Research: Helicobacter pylori. Key Document. WHO, Geneva. Accessed http://www.who.int/vaccine_research/documents/Helicobacter_pylori/ en/.

Xia YC, Jiang HX, Dian SY, Huang ZN (2007). The clinical effect of Esomeprazole-based short-range triple therapy for Helicobacter pylori-infectious duodenal ulcer. Clin. Focus 22:268-270.

Xu CX, Xiao LJ, Zou HF (2010). Effect of bifid triple viable on peptic ulcer patients with Helicobacter pylori infection. J. Cent. S. Univ. Med. Sci. 35:1672-7347.

Yang ZX (2006). The prevention and control of probiotic bacteria to Helicobacter pylori infection. Chin. J. Dig. 26:850-851.

Zhang WD (2004). Current consensus concepts of Helicobacter pylori. Chin. J. Dig. Dis. 24:126-127.

Zhou DY, Zhang WD, Wang JD, Xu KQ (1997). Consensus report of Chinese Medical Association's Second National Academic Seminar on Helicobacter pylori. Chin. J. Dig. Dis. 36:440. 